\title{
The Application of the Four-level Skills Training System in the Aviation Equipment Maintenance Practical Teaching
}

\author{
Wu Yong ${ }^{a}$, Li sihai ${ }^{b}$, Ren Binbin ${ }^{c}$, Chen Hong $^{d}$ \\ Sanya Aviation and Tourism College, Hainan, China 572000 \\ a1692346335@qq.com, ${ }^{b}$ shai_li@hnair.com, ${ }^{\text {bbb_ren@163.com, }{ }^{d} 405589069 @ q q . c o m}$
}

Keywords: aircraft maintenance; practical teaching; four-level ability training system; talents training. Abstract: For those majors with strong engineering nature and high technology need, such as aviation electronic equipment maintenance, a four-level ability training system is designed, all practical teaching links are reformed and corresponding supporting measures as well as multiple teaching methods are adopted. With the continuous development of the reform in practical teaching, its quality is gradually raising, the students' professional abilities and comprehensive qualities is further improving and the cultivation of maintenance talents has achieved sound results.

\section{Introduction}

The key to improve the teaching quality of vocational education is to reform the practical teaching. A major program now facing the current vocational education is how to motivate students' learning interests, improve the teaching quality of practical teaching and exert the outstanding role of practical teaching through a set of reforming measures so that to cultivate skilled talents that meet the requirements of enterprises.

Avionic electronic equipment maintenance major in Sanya Aviation and Tourism College (hereinafter referred to as "the college") establishes the four-level skill training system according to the principle of "taking being qualified for the professional post demand as the goal, comprehensive professional ability training the main line and satisfying the employer's requirements the quality standard" and the law of skill acquisition. It has explored a practical teaching mode for maintenance talents' skill training.

\section{The composition of the four-level skill training system}

Through a large number of investigations and surveys and analyses on the aviation aircraft maintenance enterprises' requirements for talents, combined with the actual job posts of our college's graduates, and according to the principle of "taking being qualified for the professional post demand as the goal, comprehensive professional ability training the main line and satisfying the employer's requirements the quality standard" and the law of skill acquisition, the four-level skill training system for practical teaching were established: basic skill training -operation skill training -practice skill training -maintenance skill training. Practice projects were jointly developed under the guidance of enterprise experts and front-line qualified workers and with the licensure examination and training outline for aircraft maintenance personnel and the typical working mission of HNA aircraft maintenance as references.

\section{The application of the four-level skill training system in the practical teaching of aviation electronic equipment maintenance}

\section{The establishment of the four-level skill training system for practical teaching}

By understanding the aircraft maintenance manuals of the Boeing Company and the Airbus SAS, two major airplane makers, from which we derived the specific ability objectives needed for completing aircraft electronic equipment maintenance. Following the law of gradually progressive skill development, the concept of "four-level ability objective" was therefore brought up, based on which the four-level skill training system for practical teaching was established. 
The first level is basic skill training, which aims to develop the students' basic skills needed in actual posts, such as the identification and correct use of basic maintenance tools and measuring implements, insurance making, the basic skills for electronic welding, the identification and use of tools for standard electronic practice. The major corresponding courses are Fundamental Theory of Electrical Maintenance, Fundamental Theory of Analog Electronic, Fundamental Digital Electronic Technique, Fundamental Theory of Maintenance Technology etc. The basic skill training shall be completed during the in-class practice and the two-week concentrated training of some professional foundation courses. Therefore, we design and develop training projects such as use of Multimeter and Oscilloscope, using 555 chips to produce rectangular pulse, design of controlling the circuit with sound and light and welding. The level of training is completed in all training rooms.

The second level is operation skill training aiming at training students' cognitive competence for aircraft system and electronic system and the assembling and disassembling competence of all parts of the aircraft. The operation skill training is carried out during the in-class practice of specialized courses. The corresponding training projects include the cognition of TCAS (traffic collision and alert system) in Navigation System and the cognition of antenna in Dornier 328. This level of skill training has been close to job skill training, and the training project takes aircraft maintenance manual and part of the enterprise's worksheets as references, jointly developed by college and enterprise based on the practice condition of the college. We adopt different teaching methods during the training according to the vocational education law, such as guiding teaching and group teaching. And the place of learning and practice training are often in multifunction classroom or the training plane. This level of training focuses on the integration of theory and practice and blurs the bound between theory and practice, during which practice will be conducted in theory courses and explanation be delivered in practice. The operation skill training is mainly for building solid foundation for the subsequent practice skill training.

The third level is practice skill training, which aims at training students to independently finish comparative comprehensive "simulate" actual working tasks, for example, the examination and maintenance of static discharge wick of Dornier plane are mainly completed in the training aircraft. The practice skill training mainly adopts project-oriented teaching method. The projects selected are the typical tasks from the front line work provided by enterprises, and they are consistent with the students' working contents after graduation. The supporting experiment equipments are the two training aircrafts donated by enterprises and all the tools and materials for the industry qualification certificate examination.

In this level of skill training, we conduct some expanding skill training except the job skill training. We set up Electronic Innovation Association and Model Airplane Association and we also organize students to take part in extracurricular scientific and technological activities to broaden students' visions, further motivate students' learning interests and expand their abilities of independently analyzing and solving problems. Every year, the college holds Vocational Skills Contest and organizes students to attend provincial Vocational Skills Contest, Electronic Design Contest and Venture Contest to create sound environment for enhancing students' innovative design skills.

The fourth level is maintenance skill training, aiming at training students direct mount guard ability, which is the ability to maintain the flying airplane. The maintenance skill training is conducted when students complete the three-level ability training, being assigned to off-college training bases in the end of the fifth semester, during their substituted post exercitation period and within a year's working. In this stage, "apprenticeship system" that experienced workers from front working line teaches a student is adopted, so that the airplane electronic maintenance tasks can be completed in the real scenarios and the seamless connection between college and enterprise is realized for ability training. Usually, students need to complete a detailed internship report and the enterprise needs to issue internship identification with seal. The assessment and evaluation of the internship performance are jointly made by the supervisor and leader in the enterprise as well as the team-lead teacher.

The four-level ability training for practical teaching and all kinds of college and provincial vocational skills contests organized every year help to enhance students' post professional competence and innovation ability, which also yield fruitful results. Our students have won more than ten awards in 
provincial level and above since 2009. Our students majoring electronics won the first place in Hainan Provincial Professional Skills Contest in 2013 and participated in the national contest on behalf of Hainan Province. Our graduates in 2014 outstood in the Model Aircraft Flying Game in the college winning the favor of the employers and signed the employment agreement in advance.

Maintenance style and overall qualities are formed in the process of conducting the four-level ability training for practical teaching

\section{Paramilitary management and maintenance culture construction}

Through doing morning and evening exercises, wearing uniforms in practice and training course and straightening all working attendance checking systems, the paramilitary management is realized and sense of discipline is reinforced. The activities such as maintenance subject education for freshmen, every year's maintenance lectures, maintenance oath and professional skills contests create a strong maintenance cultural atmosphere.

\section{Front work line simulation and standard operation}

Simulated working environment is created in the process of operation training and the integrating skills training and the actual working procedures are imitated according to the enterprise's working stand. The maintenance quality of operation following standards is realized and safety awareness is developed through working links such as wearing training suits, querying manuals, borrowing tools, operating with bills and "three counts" (count before work, count when place changes and count after work).

\section{Practice in groups and coordination in teams}

As for the organization forms in practical teaching, practice in groups is usually adopted, for example, in the practical course of electronic product manufacturing, three students will be in a group. They could coordinate with their own tasks increasing effectiveness, while they could also jointly consult cooperating as a team. Competition exists among groups while within the groups students help each other and solve problems.

\section{The initial effect of the four-level ability training system for practical teaching}

With the application of the four-level ability training system in practical teaching, the cultivation effects in terms of students' professional competence, professional qualities and innovation abilities are showing up. The satisfaction of enterprises is gradually growing, students' counterpart employment rate is steadily increasing within a half year, and the income of maintenance graduates ranks in the front among the higher vocational college students' job posts.

In the annual report on the college's social needs and training quality provided by MyCOS in 2014, we found that in the core knowledge system, the satisfaction on computer science and electronics of graduates in 2013 achieved $91 \%$; their overall innovation competence satisfaction reached at $86 \%$ which is higher than the average level of higher vocational colleges in the whole nation; as for the qualification improvement, $83 \%$ of the graduates in 2013 felt they made great progress in team working; while in 35 basic working abilities, satisfactions in terms of communicating, handling problems and solving difficulties were all above $80 \%$.

\section{Several aspects needed attaching importance to in the four-level ability training system for practical teaching}

\section{Constantly improve the candidates' quality in this major}

Major of aviation electronic equipment maintenance has high requirements in engineering courses, techniques and comprehensive qualities. The working post of airplane maintenance needs not only the basic professional knowledge on aviation and electronic, but needs strong practical abilities, and meanwhile, it needs students to have English skills and higher overall qualities, therefore, the threshold of employment in this industry is relatively high. Then we will constantly reform practical teaching and reinforce the training in basic English and professional English to improve talents quality so as to increase our students' employment rate within the industry, which could in return attract more outstanding students to register in this major. 


\section{Implement combination of learning with working and college with enterprise}

While carrying out the four-level ability training system in practical teaching, the talent training program, practice project and practical worksheet need the joint participation and formulation of college and enterprise. Even though Hainan Airlines Group has favorable policy supporting, its working mechanism and supporting measures still need to be continuously improved in actual implementation. Teachers also need to actively participate in the research and development of enterprise's new product, new process and new technology; they will serve the enterprise with their intellectual supporting through continuous study as well; and they could organize students to serve production so as to truly combine college with enterprise.

\section{Stress the cultivation of students' standard consciousness and safety awareness}

A major aspect of maintenance major that is different from others is its higher quality standard and safety operation specification. In the process of conducting practical teaching, students' standard consciousness and safety awareness should be put into the whole training and should be reflected in the practice evaluation and assessment.

\section{Further enhance basic English and specialized English learning}

Another significant character of maintenance major is the importance of English. Because the civil aircrafts are mainly produced by Boeing Company and the Airbus SAS, all materials for airplane maintenance provided are in English. Work can hardly be done if the worker lacks English reading and writing competence. Besides, students in higher vocational college are often poor in English reading and writing, so it is very importance to enhance English learning and improve their English reading and writing competence.

\section{Conclusion}

In modern higher vocational education, practical teaching possesses the equally significant and irreplaceable position and function with theory teaching. It will effectively achieve the objective of talents training through a set of practical teaching activities with purpose, plan and system such as experiment, internship and professional practice. Under the guidance of vocational education teaching theory of "combination of learning with working" and "systematic work process", with the firm support form Hainan Airlines Group and through giving full play to late-mover advantage, we have from a high starting point explored a practical teaching mode highly matched with this major, which is the four-level skills training system. It effectively improves the professional skills of maintenance majors and their overall accomplishment and it also provides more technical skilled talents with high qualities to Hainan Airlines Group and the civil aviation aircraft maintenance industry.

\section{Acknowledgements}

This work was financially supported by the Research project of teaching reform of higher education in Hainan Province (No: Hnjg2015ZD-19), (No: Hjjg2013-75).

\section{References}

[1] Wang Defeng,Deng Heping. Education and social development in postwar Germany[J]. Journal of Higher Education, 1999,20(3): 94-97.

[2] Jiang Kun. The history of high-speed development of postwar Japanese economy[J].Economic and technological cooperation information, 2013,142(15):7.

[3] Fan Xiudi,The overseas higher vocational education characteristics[J],Study on Higher Education, 2004, 19-24.

[4] Xie Liuzhi,Li Yunli. The problem existing in our country's occupation education[J], Economic Research Guide,2015,259(5): 120-121. 
[5] Zhao Haoxing .Discussion on the practice teaching mode of higher vocational school enterprise cooperation,Journal of Zhejiang Normal University,2001[4]

[6] Zhu Fanglai.Comparative Study of Chinese and German Higher Vocational Education,Higher Education Exploration,2015[3].

[7] Zhang Yu.The Enlightenment of Korea's Higher Vocational Education Development to China,Vocational Education, G719.1,2015. 